\title{
Isolated Eyebrow Alopecia: When the Dermoscope Makes the Diagnosis
}

\author{
Khadija Elboukhari Hanane Baybay Sara Elloudi Zakia Douhi \\ Fatima Zahra Mernissi \\ Department of Dermatology, University Hospital Hassan II, Fez, Morocco
}

\section{Question}

A 17-year-old adolescent with a history of atopic dermatitis and acne vulgaris was out of school because of family financial difficulties and working for a carpenter instead. He came to our department for eyebrow hair loss, without hair loss in other body sites. Upon dermatological examination, we noted a rarefaction of hair in both eyebrows without erythema, and the hair pull test was negative (Fig. 1). The eyelashes, scalp, and body hair examination was normal. Further dermatological examination showed excoriated papules with retentional acne and diffuse xerosis.

What is your diagnosis?

Fig. 1. Bilateral eyebrow hair rarefaction in an adolescent of 17 years.

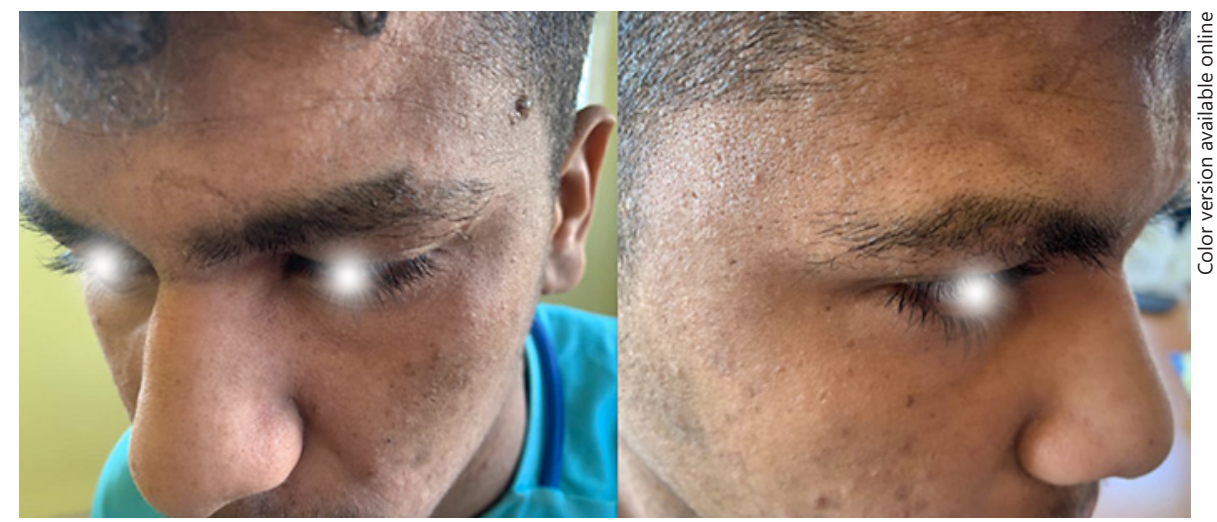

Khadija Elboukhari

Department of Dermatology, University Hospital Hassan II

KM 2,200 Sidi Harazem Street

Fez 30070 (Morocco)

elboukharikhadija89@gmail.com 


\section{Answer}

In front of this clinical presentation, we evoked alopecia areata, frontal fibrosing alopecia, and trichotillomania. Using our dermoscope, we found broken hairs with different fracture levels, dark dots of different sizes, the V sign, and tulip hairs were noted (Fig. 2). These signs are associated with trichotillomania. Besides, except for pseudomonilethrix hairs that were found upon dermoscopic examination of the left eyebrow, we did not find other trichoscopic clues pointing to alopecia areata, such as exclamation mark hairs, yellow dots, or short vellus hairs. This finding made us discard the diagnosis of eyebrow alopecia areata without excluding a probable association with trichotillomania. A psychological examination was conducted, and a parental conflict was declared by the patient, who denied having the habit of plucking his eyebrows. We indicated a psychiatric follow-up combined with treatment with $\mathrm{N}$-acetylcysteine at the dose of $1.2 \mathrm{~g}$ twice a day.

According to the Diagnostics and Statistic Manual of Mental Disorders, 4th edition (DMS-IV), trichotillomania is a type of hair loss secondary to repetitive self-pulling of hairs [1]. It was reclassified as an obsessive-compulsive disorder and related disorders (OCDRD) in the fifth edition of the Diagnostic and Statistical Manual of Mental Disorders (DSM-V). This psychiatric disorder is characterized by repetitive, intentional behavior [2]. It affects $1 \%$ of the general population [3] and is more frequent in children than in adults [4]. This disorder mainly affects the scalp, but all body hair is affected, including eyelashes $[5,6]$, eyebrows [7], even the beard [8] and the pubic hairs [2,7]. The etiology is complex and suggests a psychosocial stressor within the family or environment [2]. The majority of patients with this disorder deny the factitious origin of their hair loss, which was also the case in our patient. The affected site being limited to the eyebrows makes the diagnosis difficult. Dermoscopy is a great help in the diagnosis of trichotillomania. The dermoscopic features of trichotillomania correspond to pilar fractures at different levels [9]. Black dots corresponding to broken hairs before scalp/skin emergence are evident. The V sign corresponds to two broken hairs emerging from the same pilar orifice. Flame hairs

Fig. 2. Trichoscopic signs in favor of trichotillomania. Blue circles indicate the $\mathrm{V}$ sign. Green circles indicate broken hairs at different levels. Red circles point to tulip hairs. Yellow circles show black dots of different sizes, which is a sign in favor of alopecia areata. Presence of pseudomonilethrix hairs is marked by pink circles.

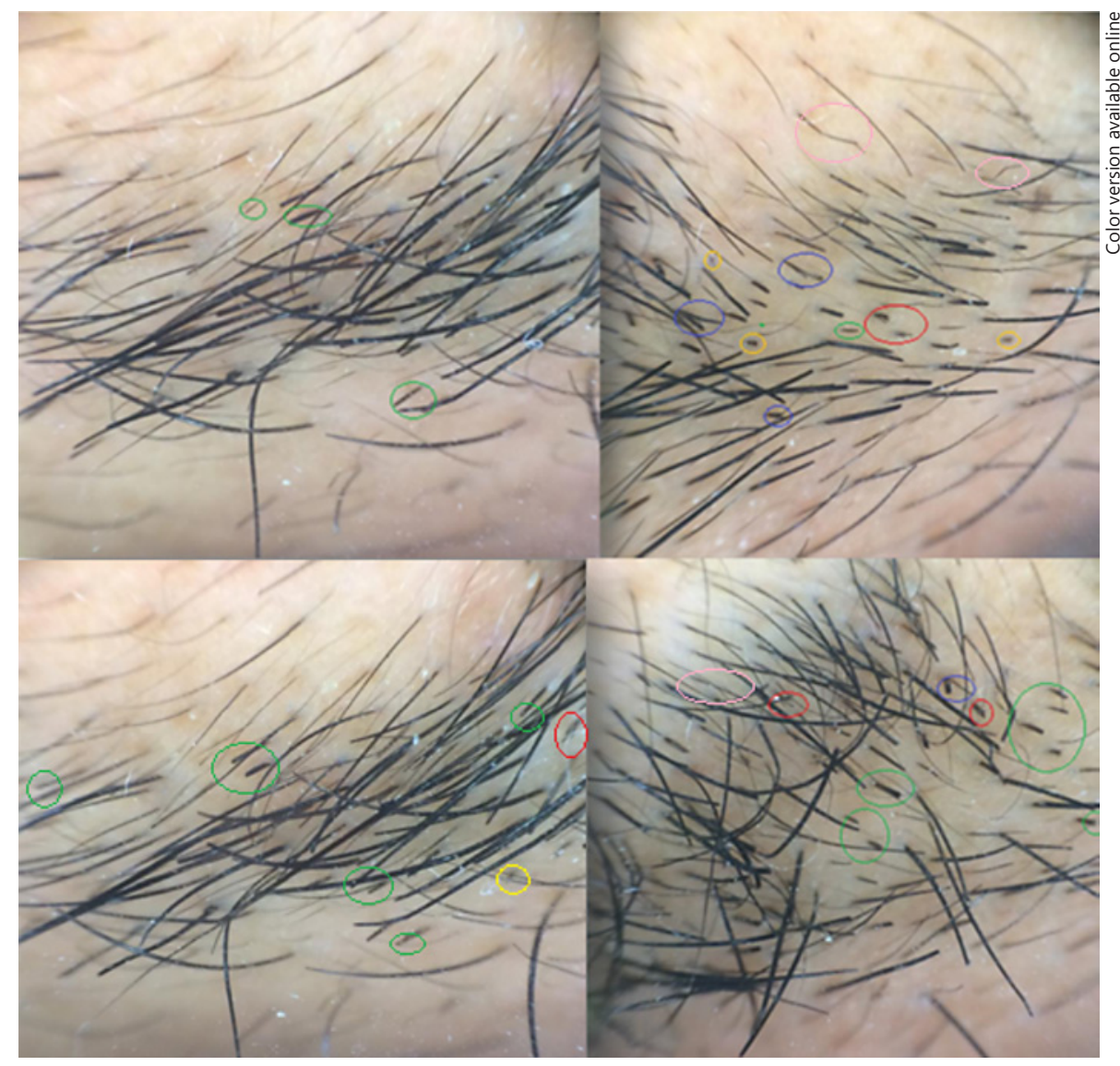


and broken hairs, hair powder (totally damaged hairs), hook hairs with a curved distal extremity, and tulip hairs with a darker, tulip flower-shaped end are findings described as trichotillomania in several studies $[9,10]$. In our patient, the conflictual environment and the facial excoriated papules that reflect underlying stress supported our diagnosis of eyebrow trichotillomania. The mainstay of therapy is psychiatric management using cognitive behavioral therapy with selective serotonin reuptake inhibitors. $\mathrm{N}$-acetylcysteine may be used, as this glutamate-modulating agent is a promising treatment option that can avoid side effects of selective serotonin reuptake inhibitors. A good response was seen in several reported cases [11].

\section{Acknowledgement}

We are indebted to the patient for giving us the consent for publication.

\section{Disclosure Statement}

The authors have no conflicts of interest to declare.

\section{Funding Sources}

The authors did not receive any funding.

\section{Author Contributions}

All authors contributed to the conduct of this work. All authors also state that they have read and approved the final version of the manuscript.

\section{Keywords}

Eyebrow · Alopecia $\cdot$ Trichotillomania

\section{Statement of Ethics}

The patient's consent was obtained for the pictures and eventual publication.

\section{References}

1 Zímová J, Zímová P. Trichotillomania: Bizzare Patern of Hair Loss at 11-Year-old Girl. Acta Dermatovenerol Croat. 2016 Jun;24(2): 150-3.

2 Bohne A, Savage CR, Deckersbach T, Keuthen NJ, Wilhelm S. Motor inhibition in trichotillomania and obsessive-compulsive disorder. J Psychiatr Res. 2008 Jan;42(2):14150.

3 Gershuny BS, Keuthen NJ, Gentes EL, Russo AR, Emmott EC, Jameson M, et al. Current posttraumatic stress disorder and history of trauma in trichotillomania. J Clin Psychol. 2006 Dec;62(12):1521-9.

4 Gallouj S, Rabhi S, Baybay H, Soughi M, Meziane M, Rammouz I, et al. Trichotemnomanie associée à une trichotillomanie : intérêt diagnostique de la dermoscopie. Ann Dermatol Venereol. 2011 Feb;138(2):140-1.
5 Touzani KD, Lamari Z, Chraibi F, Abdellaoui M, Andaloussi IB. La trichotillomanie des cils: à propos d'un cas. Pan Afr Med J. 2017 Oct; 28:142.

6 Ubukata S, Mimura T, Watanabe E, Matsumoto K, Kawashima M, Kitsu K, et al. Bilateral Trichotillomania of Eyelashes Triggered by Anxiety due to Nocturnal Enuresis: A Case Report. Case Rep Ophthalmol Med. 2019 Jun; 2019:4650217.

7 Radmanesh M, Shafiei S, Naderi AH. Isolated eyebrow and eyelash trichotillomania mimicking alopecia areata. Int J Dermatol. 2006 May;45(5):557-60.
8 Cutrone M, Grimalt R. The Dermoscopic "Pluck Out Sign" for Beard Trichotillomania. Skin Appendage Disord. 2018 Jan;4(1):15-7.

9 Rakowska A, Slowinska M, Olszewska M, Rudnicka L. New trichoscopy findings in trichotillomania: flame hairs, V-sign, hook hairs, hair powder, tulip hairs. Acta Derm Venereol. 2014 May;94(3):303-6.

10 Martín JM, Montesinos E, Cordero P, Gonzalez V, Ramon D. Trichoscopy features of trichotillomania. Pediatr Dermatol. 2019 Mar;36(2):265-7.

11 Barroso LA, Sternberg F, Souza MN, Nunes GJ. Trichotillomania: a good response to treatment with $\mathrm{N}$-acetylcysteine. An Bras Dermatol. 2017 Jul-Aug;92(4):537-9. 